\title{
AMERICAN JOURNAL OF ORAL MEDICINE: A New Challenge for the Third Millennium
}

\section{Giulio Fortuna ${ }^{*}$}

Received: 09 February 2015; Returned for revision: 18 April 2015; Received in revised form: 27 April 2015; Accepted: 27 April 2015; Published online 26 May 2015

(C) The author(s) 2015. Published with open access at www.uscip.us

The American Journal of Oral Medicine (AJOM) was conceived after the congress "Frontiers in Oral Medicine 2014," hosted by the American Academy of Oral Medicine (AAOM) in Orlando, Florida (USA), with an active participation of three other academic partners, the European Association of Oral Medicine, the British Society for Oral Medicine, and the Oral Medicine Academy of Australasia.

This exciting conference showed that the journey is still tremendously long: despite more than 50 years of activity, oral medicine still lags behind in comparison with other medical specialties, and young researchers have received fewer chances to show their work.

Research in oral medicine requires a strong motivation not only from a financial standpoint (more funds) but also from a professional/human one (more responsibility). We need to move towards a new era of clinical research, possibly made up of more randomized controlled trials and prospective studies, and basic science research, to better define etiology, pathophysiology, and prognosis of many oral-pharyngeal diseases.

Oral medicine is in desperate need of this kind of new, mostly translation research, in which we are very far behind; there are too many open questions, even on those oral-pharyngeal diseases that we commonly see in our daily practice, such as oral lichen planus.

So, the idea of a new journal in the field of oral medicine was born through a strong need to revolutionize this discipline, providing an additional opportunity mostly to young oral medicine scientists to have their own research propagated all over the world and to cast oral medicine into the third millennium with their love, knowledge, and hard work.

Another important reason for a new journal was related to the paucity of journals dealing exclusively with oral medicine, which results in a reduced space for publishing even excellent papers and a very low rate of acceptance.

*Corresponding e-mail: giulio.fortuna@gmail.com

1 Department of Oral Medicine, Carolinas Medical Center, 1000 Blythe BLVD-28203-Charlotte, NC - USA 


\section{Giulio Fortuna \\ American Journal of Oral Medicine (2015) Vol. 1 No. 1 pp. 1-4}

Conversely, the $A J O M$ is an electronic journal with virtually no limitation to publishing articles. Therefore, if new and innovative research in oral medicine occurs in the near future, we will have a plethora of interesting data and results, for which new, strong, high-quality, freely available and easily accessible resources will be absolutely necessary in order to disseminate them and, hopefully, the AJOM will play a pivotal role in this. Our ultimate goal is to attract the best research and most innovative ideas, and to be a point of reference in the panorama of oral medicine. Hence, the only requisite for acceptance will be scientific excellence.

Why should authors choose the AJOM? When this journal was conceived, the main goal was to have a journal that was both specifically directed to oral medicine specialists and capable of fostering an interdisciplinary contribution with other medical specialties, such as dermatology, gastroenterology, otorhinolaryngology, internal medicine, psychiatry/psychology, endocrinology, and provide them with the most relevant and up-to-date educational material in the field of oral medicine.

In addition, but no less important, the $A J O M$ is an open journal, fully online, with no associated publication fees either for editorial board members or authors. This allows unrestricted access to a wider readership in a time-efficient manner and a greater dissemination of scientific research, with the subsequent increase in the visibility and impact of published works.

I do strongly believe that the mandate of an editor-in-chief is to generate a high-quality international journal. Therefore, with this in mind, I was pleased to contact as associate editors two eminent scientists with very strong backgrounds in the field of clinical and basic science research in oral medicine.

Dr Francina Lozada-Nur is currently Professor Emerita of the University of California, San Francisco, USA. She was my mentor when I was a student and still represents for me a fount of indepth knowledge. The entire world of oral medicine recognizes her outstanding contribution, mainly in the field of oral-pharyngeal blistering diseases, she being a pioneer in studies on erythema multiforme and the use of corticosteroids. Dr Nicola Cirillo is currently Associate Professor of oral medicine at the University of Melbourne, Australia. He is a very well-known scientist, whose contribution to translational research in oral medicine, mainly in the pathogenesis of pemphigus vulgaris, has provided a more thorough comprehension of such a devastating disorder, opening new frontiers for possible therapeutic implications.

Similarly, I am also very proud to announce a very strong list of editorial board members, whose constant scientific contributions testify to their knowledge in the field of oral medicine and I do firmly believe that their commitment and strong expertise will attract the very finest scientists and represent the highest standard of peer review.

My sincerest appreciation is extended to the associate editors and all members of the editorial board, who will help me in areas of oral medicine beyond the bounds of my personal expertise in order to implement the AJOM. Thus, I am confident that the AJOM will become one of the best sources of information in the field of oral medicine over the next few years. Of course, I will continue to work hard in finding and recruiting even more scientists in the field of basic science and clinical research in oral medicine, who are willing to serve as editorial board members for the journal. 


\section{Giulio Fortuna \\ American Journal of Oral Medicine (2015) Vol. 1 No. 1 pp. 1-4}

As the $A J O M$ has been conceived as a peer-reviewed, open-access international journal to reflect the interest and needs of multi- and interdisciplinarity, covering all aspects of oral medicine in the field of clinical and basic science research, topics of interest will include - but will not be limited to epidemiology, pathophysiology, genetics, immunology, cellular/molecular biology, diagnosis and therapeutics, clinical trials, and prevention.

I have personally chosen different categories of articles: editorials, original and review articles to represent the core of the journal (Kendal, 2003; Humphrey et al. 2008; Writing Group for the N. E. T. i. P. D. I., et al. 2015), opinion articles to provide readers with a high level of expertise on specific topics and controversies in oral medicine, commentaries to accompany an article published in the journal, and letters to the editor to either foster a discussion on any of the published articles or submit single case report/s or adverse drug reactions in oral medicine.

However, in order to give an innovative feature to the oral medicine literature and provide a more advanced educational level, I have also introduced two different categories of articles currently not present in any other journal dealing with oral medicine: Challenging Cases, where scientists are welcome to submit 1-3 cases that represented very difficult cases in terms of diagnosis and/or treatment. Authors are encouraged to explain in detail the entire diagnostic process, which might have taken several months or years, as well as the challenge in the therapeutic process, mostly for cases that are refractory and unresponsive to conventional therapies. Similarly, I have added another section named Images in Oral Medicine, where authors are encouraged to submit unusual clinical and/or radiological cases, which while not meriting a place as a case report or challenging case may still provide intriguing and important information to share with the world of oral medicine and medicine-dentistry in general.

These two types of article should have educational purposes not only for oral medicine specialists but also more generally for all oral health care providers, in order to increase clinical understanding globally, and so provide a more accurate and appropriate health care.

I very much hope that your contributions will keep this journal alive and competitive, helping us to move forward and open a new era in the field of oral medicine. We are very happy and proud to serve the scientific community over the coming years.

I would like to conclude with a few words in memory of one of the greatest scientists we have ever had in the field of oral medicine over the past 50 years, who was also one of my mentors and who recently passed away: Dr Sol Silverman Jr, Professor Emeritus at the University of California, San Francisco, USA, whose scientific contribution has represented and will represent a milestone in the field of oral medicine for future generations. We all owe him an immense debt of gratitude.

\section{Acknowledgements}

Prof. Francina Lozada-Nur and Prof. Nicola Cirillo for their invaluable feedback

\section{Conflict of Interest}

None 


\section{Giulio Fortuna}

American Journal of Oral Medicine (2015) Vol. 1 No. 1 pp. 1-4

\section{Funding}

None

\section{References}

Kendall, J. M. (2003). Designing a research project: randomised controlled trials and their principles. Emerg Med J, 20(2), 164-168.

http://dx.doi.org/10.1136/emj.20.2.164

Humphrey, L. L., Fu, R., Buckley, D. I., Freeman, M., \& Helfand, M. (2008). Periodontal disease and coronary heart disease incidence: a systematic review and meta-analysis. J Gen Intern Med, 23(12), 2079-2086. http://dx.doi.org/10.1007/s11606-008-0787-6

Writing Group for the N. E. T. i. P. D. I., Kieburtz, K., Tilley, B. C., Elm, J. J., Babcock, D., Hauser, R., et al. (2015). Effect of creatine monohydrate on clinical progression in patients with Parkinson disease: a randomized clinical trial. JAMA, 313(6), 584-593.

http://dx.doi.org/10.1001/jama.2015.120 